\title{
Long-term changes in adipose tissue in human disease
}

\author{
Caroline M. Pond \\ Department of Biological Sciences, The Open University, Milton Keynes MK7 6AA, UK
}

\begin{abstract}
Redistribution of white adipose tissue is a long-term symptom of several chronic diseases. Although the roles of adipocytes in acute illness have been thoroughly studied, how or why shortterm responses of adipose tissue to disease sometimes produce long-term redistribution, and the causal relationship between the anatomical changes and the associated metabolic syndromes are poorly understood. The present paper reviews explanations for the redistribution of adipose tissue after infection with HIV, and in Crohn's disease; both conditions that share the peculiarity of selective expansion of certain adipose depots while others are depleted. HIV adipose tissue redistribution syndrome (HARS) develops gradually after several months of infection with the HIV both in untreated patients and in those taking protease inhibitors and nucleoside reverse transcriptase inhibitors. Some current theories about the causes of HARS are critically assessed, and reasons presented for implicating local interactions between the immune system and perinodal adipocytes. Some evolutionary aspects of conspicuous long-term changes in the distribution of human adipose tissue are discussed. Adipose tissue acts as a social signal, indicating dietary history and previous exposure to pathogens. A distinctive symptom of Crohn's disease is selective enlargement of the mesenteric adipose tissue near the diseased lymph nodes and intestine. Perinodal adipocytes have site-specific properties not found in adipocytes from nodeless depots, such as perirenal and epididymal, that may equip them to interact locally with lymph-node lymphoid cells, making polyunsaturated fatty acids selectively and rapidly available to activated immune cells. Studies of the time course of activation of perinodal adipocytes via the lymph nodes they enclose indicate that prolonged or frequent stimulation recruits more adipocytes to control by immune cells, which may lead to selective enlargement of node-containing depots. These concepts suggest hypotheses about HARS and the anomalous development of mesenteric adipose tissue in Crohn's disease that could form the basis for further investigations.
\end{abstract}

\section{HIV: HIV adipose redistribution syndrome: Crohn's disease: Perinodal adipocytes:} Antiretroviral drugs

The short-term changes in the large conspicuous depots of adipose tissue during acute infection and inflammation have been thoroughly studied; appetite suppression mediated by leptin, tumour necrosis factor and other cytokines, combined with the autonomic nervous system, stimulate adipose tissue to large often sustained increases in secretion of the products of lipolysis, a variety of informational molecules and probably also glutamine (Frayn et al. 1991; Grünfeld \& Feingold, 1992; Digby, 1998). The rise in blood concentration of non-esterified fatty acids is easily measured, and at least some of the cytokines found in the circulation can be attributed to adipose tissue (Torpy et al. 1998). The long-term changes in the distribution of adipose tissue in human diseases such as non-insulin-dependent diabetes mellitus (NIDDM) and Cushing's syndrome have also been thoroughly described (Lonn et al. 1994; Björntorp, 1996). Several hypotheses that integrate the anatomical features of these disorders with the alterations in blood lipids and insulin sensitivity have been proposed (Björntorp, 1997; Chrousos, 2000; Frayn, 2000), although none of the hypotheses is entirely satisfactory or comprehensive.

Although adipose tissue is now accepted as having much wider involvement in whole-body metabolism than was believed a few years ago (Mohamed-Ali et al. 1998; Pond, 1999), we still do not understand how or why short-term responses of adipose tissue to disease sometimes produce long-term redistribution, or the causal relationship between the anatomical changes and the associated metabolic syndromes. The present paper reviews explanations for the

\footnotetext{
Abbreviations: HARS, HIV adipose redistribution syndrome; NIDDM, non-insulin-dependent diabetes mellitus; NRTI, nucleoside reverse transcriptase inhibitors.

Corresponding author: Dr Caroline Pond, fax +44 1908 654167, email C.M.Pond@open.ac.uk
} 
redistribution of adipose tissue in two such conditions, infection with HIV and Crohn's disease, and suggests some unifying concepts that could form the basis for further investigations.

\section{The redistribution of adipose tissue in HIV infection}

Improvements in antiviral therapy have greatly increased longevity and quality of life for individuals infected with HIV. This success has led to the identification, in 1997, of several side effects, among them long-term changes in the distribution of adipose tissue, the HIV adipose redistribution syndrome (HARS), also known as lipodystrophy or lipoatrophy (Shaw et al. 1998). Although worse while proliferation of the HIV is curtailed by frequent doses of antiretroviral drugs (Saint-Marc et al. 1999; Panse et al. 2000), HARS has also been described in patients in whom the progression from HIV infection to AIDS is delayed naturally (Engelson et al. 1999; Madge et al. 1999). In other words, HARS is a side effect of the establishment of successful coexistence of the virus and its host, with or without the aid of drugs.

The syndrome has been described in both sexes and in patients of all ages, including children who were infected at or shortly after birth (Jaquet et al. 2000; Miller, 2000). The manifestations are variable, but typical changes include hypertrophy of the intra-abdominal depots, probably mostly or entirely the omentum and mesentery (Engelson et al. 1999), the breasts and/or a 'buffalo hump' around the back of the shoulders (Dong et al. 1999; Kotler et al. 1999). In contrast to normal adipose tissue growth, HARS often produces asymmetrical or unilateral swelling in breasts etc. (Mauss, 2000), implying that the stimulus may be local rather than systemic. These selective enlargements are usually accompanied by depletion of the superficial adipose tissue on the buttocks, thighs, arms and legs, sometimes to the extent that cutaneous veins become clearly visible (Carr, 2000). In severe cases, the corpus adiposum buccae (Bichat's pad), periorbital adipose tissue and other metabolically-inert depots of the face shrink, producing the hollow cheeks and sunken eyes that are characteristic of elderly and terminally ill people (Carr, 2000; Panse et al. 2000). The sparse clinical data available indicate that HARS is as bad or worse in women (Gervasoni et al. 1999), although the majority of those who complain are homosexual males living where the availability of antiretroviral drugs keeps them alive and fairly healthy for long enough for these symptoms to become severe.

The involvement of large non-motile non-dividing cells such as adipocytes in a pathology of small mobile usually rapidly-dividing cells such as lymphocytes came as a surprise to physicians, immunologists and virologists. Like the changes in the distribution of adipose tissue in NIDDM, HARS develops slowly and insidiously, usually taking months or years to become conspicuous, and manifestations are variable. The main contrasts arise from the facts that NIDDM patients are mostly middle-aged or elderly, female and overweight, and their site-specific changes in adipose tissue are inconspicuous, difficult to quantify and easily attributed to normal ageing. Those suffering from HARS are mostly young and underweight; even quite minor selective expansion or depletion of particular adipose depots is quickly noticed.

The two main classes of antiretroviral drugs work in contrasting but synergistic ways. Protease inhibitors prevent the virus from infecting more cells by interfering with the final stages of assembly of its capsid proteins. Nucleoside reverse transcriptase inhibitors (NRTI) stop the formation of a DNA copy of the viral RNA, thereby preventing duplication of the viral genome in host cells. Many patients are treated with combinations of protease inhibitors and NRTI, which must be taken continually and in large doses to be effective. HARS can occur at constant, increasing or decreasing body mass, and with or without changes in average energy intake. In spite of the contrast in mode of action of the two types of drugs, it is very difficult to identify consistent differences in the manifestations of HARS in patients who have been taking protease inhibitors or NRTI, or combinations of both (Saint-Marc et al. 1999, 2000; Behrens et al. 2000).

Intensive chemotherapy with these antiretroviral drugs often produces nausea, diarrhoea, lethargy, abnormal sensations in peripheral nerves and mental confusion (Kolson et al. 1998). Most patients who have been HIVpositive for some time show metabolic changes characteristic of chronic infection (Vigouroux et al. 1999); glucose uptake is impaired (although frank diabetes is rare), and the concentrations of blood lipids are elevated. At first, these symptoms were thought to be causally related to HARS, but the search for correlations between the magnitude and time of onset of the anatomical changes and metabolic abnormalities such as insulin resistance and hyperlipidaemia has proved as unrewarding as similar endeavours for NIDDM. Most experts now regard HARS and the metabolic changes as separate syndromes (Safrin \& Grünfeld, 1999; Hatano et al. 2000; Panse et al. 2000).

A wide range of hypotheses have been proposed to account for HARS, some of which are listed in Table 1, together with a summary of some of their obvious deficiencies. Structural and metabolic anomalies of mitochondria can be detected in biopsies of cardiac muscle and the liver (de la Asuncion et al. 1998; Brinkman et al. 2000), but these effects are not so severe as to be incapacitating, even in organs such as the heart that depend heavily on mitochondrial metabolism. A few cases of fatal impairment of liver function have been reported (Moyle, 2000), but most patients are well enough, even after years of chemotherapy, to complain about a cosmetic disorder such as HARS. Pregnant monkeys given large doses of one of the most widely used NRTI, zidovudine (3'-azido-3'deoxythymidine), nonetheless produce full-term viable neonates, albeit with detectable abnormalities in their muscles (Gerschenson et al. 2000). The main objections to all hypotheses based on molecular similarities between drugs and key metabolites are that HARS can occur in untreated patients, and protease inhibitors and NRTI are chemically different, acting at different stages of viral proliferation, yet their effects on adipose tissue are almost indistinguishable (Saint-Marc et al. 2000); such hypotheses also fail to account for the expansion of certain depots and the simultaneous depletion of other depots. 
Table 1. Theories to explain how HIV infection and its treatment with anti-retroviral drugs cause HIV adipose redistribution syndrome (HARS)

\begin{tabular}{|c|c|c|c|}
\hline Hypothesis & Cellular mechanism & $\begin{array}{l}\text { Symptoms explained by the } \\
\text { hypothesis }\end{array}$ & Properties not explained \\
\hline \multirow[t]{3}{*}{ 'Just a form of obesity' } & \multirow{3}{*}{$\begin{array}{l}\text { Cytokines especially interferon } \\
\text { secreted by the activated } \\
\text { immune system stimulate lipid } \\
\text { storage in adipose tissue }\end{array}$} & Insulin resistance & Occurrence at falling body mass \\
\hline & & High cholesterol & \multirow{2}{*}{$\begin{array}{l}\text { Depletion of superficial adipose } \\
\text { tissue and metabolically-inert } \\
\text { depots }\end{array}$} \\
\hline & & $\begin{array}{l}\text { Growth of intra-abdominal adipose } \\
\text { tissue }\end{array}$ & \\
\hline \multirow{3}{*}{$\begin{array}{l}\text { Drugs inhibit key } \\
\text { enzymes to which } \\
\text { they are homologous }\end{array}$} & \multirow{3}{*}{$\begin{array}{l}\text { PI have about } 60 \% \text { homology } \\
\text { to cytoplasmic retinoic acid- } \\
\text { binding protein type } 1 \text { and LDL } \\
\text { receptor-related protein }\end{array}$} & Insulin resistance & Occurs in untreated HIV infection \\
\hline & & High cholesterol & Symptoms not specific to drugs \\
\hline & & Adipocytes atrophy & $\begin{array}{l}\text { Some adipose depots enlarge while } \\
\text { others shrink }\end{array}$ \\
\hline \multirow{5}{*}{$\begin{array}{l}\text { Drugs block expression } \\
\text { of key mitochondrial } \\
\text { genes causing dys- } \\
\text { function and atrophy } \\
\text { of mitochondria }\end{array}$} & \multirow{5}{*}{$\begin{array}{l}\text { NRTI designed to block viral } \\
\text { reverse transciptases also inhibit } \\
\text { DNA polymerase- } \gamma \text {, impairing } \\
\text { production of adenylate kinase, } \\
\text { ADP/ATP translocase }\end{array}$} & Cellular respiration impaired & Occurs in untreated HIV infection \\
\hline & & \multirow{4}{*}{$\begin{array}{l}\text { Muscle, liver etc. much more severely } \\
\text { affected than adipose tissue, } \\
\text { causing muscle weakness, digestive } \\
\text { problems, abnormal sensations } \\
\text { in peripheral nerves and severe } \\
\text { metabolic disorders including lactic } \\
\text { acidosis }\end{array}$} & Symptoms not specific to drugs \\
\hline & & & $\begin{array}{l}\text { Some adipose depots enlarge while } \\
\text { others shrink }\end{array}$ \\
\hline & & & $\begin{array}{l}\text { Metabolic defects probably fatal } \\
\text { before atrophy of adipocytes } \\
\text { progresses far }\end{array}$ \\
\hline & & & Should be much worse in neonates \\
\hline \multirow{2}{*}{$\begin{array}{l}\text { Abnormal local } \\
\text { interactions between } \\
\text { lymph node lymphoid } \\
\text { cells and perinodal } \\
\text { adipocytes }\end{array}$} & \multirow{2}{*}{$\begin{array}{l}\text { Prolonged activation of } \\
\text { perinodal adipocytes } \\
\text { promotes enlargement of } \\
\text { node-containing depots at the } \\
\text { expense of nodeless depots }\end{array}$} & $\begin{array}{l}\text { Changes in metabolism and blood } \\
\text { composition do not correlate with } \\
\text { anatomical features }\end{array}$ & \multirow[t]{2}{*}{$\begin{array}{l}\text { Not clear how drugs exacerbate } \\
\text { HARS }\end{array}$} \\
\hline & & $\begin{array}{l}\text { Anti-retroviral drugs are not essential } \\
\text { for symptoms and their actions are } \\
\text { non-specific }\end{array}$ & \\
\hline
\end{tabular}

PI, protease inhibitors; NRTI, nucleoside reverse transcriptase inhibitors.

Modern techniques in molecular biology are implicating viruses and other infectious agents in more and more diseases that were previously thought to be dietary, genetic or idiopathic, ranging from obesity (Dhurandhar et al. 1997) and heart disease (Ellis, 1997) to schizophrenia (Yolken et al. 2000). These chronic ailments are not associated with the development of anomalous distribution of adipose tissue, even though altered lipid metabolism and the hypothalamic-pituitary-adrenal axis are implicated in many of them, including schizophrenia (Horrobin, 1992; Laugharne et al. 1996). Any general theory about the relationship between chronic infection and adipose tissue redistribution must account for these facts. Alone among these diseases, HIV targets lymph node lymphocytes and other secondary immune tissues.

\section{Why does HIV adipose redistribution syndrome matter?}

The patients' main complaints about HARS are psychological rather than physical; the adipose tissue itself is not painful, although massive enlargements, especially of the breasts and abdomen, can become uncomfortable, and may restrict movement and distort posture. However, compared with the other complications of HIV, and the prospect of developing full-blown AIDS, HARS seems a minor problem. Nonetheless, many sufferers are sufficiently distressed by the change in their appearance that HARS is named as a major reason for discontinuing therapy (Dong et al. 1999; Behrens et al. 2000), a course that has obvious implications for the spread of HIV, and increasing debility of those individuals already infected.

Anthropologists and evolutionary biologists might explain the origins of the apparently disproportionate distress caused by HARS in terms of current theories about the relationship between sexual selection and evolutionary fitness. Research on animals, particularly birds, suggests that the manifestation of secondary sexual characters (brightly-coloured feathers, elaborate strenuous dances or songs etc.) indicates general health, especially the absence of parasites and pathogens, which are now recognised as being much more prevalent in wild populations than was previously believed; secondary sexual characters evolve to become elaborate because prospective mates use them to assess each other's evolutionary fitness (Folstad \& Karter, 1992; Zuk, 1996).

These concepts have been extended to research into human anatomy and behaviour. For example, Singh and colleagues have studied the contribution of aspects of body shape that depend partly on the adipose tissue to subjective estimates of sexual attractiveness and social status. He reports that images showing high waist:hip values (Singh, 1993), or asymmetry in conspicuous fat depots such as breasts (Singh, 1995a; Singh \& Young, 1995) are rated as undesirable as prospective sexual partners. Opinions from 
matched observers from different ethnic and cultural backgrounds hardly differ (Singh \& Luis, 1995), suggesting that the criteria may be innate. Although most of the data relate to male perceptions of potential of females as sexual partners, similar principles apply to the assessment by individuals of men's social and sexual status (Singh, 1995b). Sex differences in traditional patterns of body decoration have been interpreted along the same lines (Singh \& Bronstad, 1997). Metabolic responses to chronic infection, perhaps exacerbated by dietary excess or insufficiencies, produce long-term changes in body shape and the texture and colour of the skin and hair. If sexual partners use these characteristics as a basis for establishing and maintaining a relationship, particularly if it impacts on parental care, there is scope for the evolution under sexual selection of innate preferences for, or revulsion towards, certain aspects of appearance.

Physicians and biochemists generally avoid such evolutionary explanations, which most find boring and inconclusive, and regard 'justifications' for contemporary situations based on ancestry as irrelevant to the practicalities of diagnosis and therapy. Although many suspicions about such evolutionary psychology are fully justified, I think in this case they offer a useful perspective into why young individuals in particular should find HARS so distressing. Table 2 summarises some aspects of human biology that promote or prevent infection with pathogens and make body shape important to social and sexual success. Although several features of human behaviour and social organisation seem to make average lifetime accumulation of parasites and pathogens even worse than that of other large animals, some long-established human habits can be seen as preventing or mitigating infection. People come to recognise any significant alteration of posture, style of movement, or body shape, as a consequence of redistribution of adipose tissue or other means, as evidence of congenital defects or previous exposure to disease or injury. As body shape and texture become more important as an indicator of social and sexual status, any alterations become subject to sexual selection, a powerful evolutionary force in establishing or eliminating characteristics. Body image has long been recognised as particularly, perhaps uniquely, important to human subjects, so it is not surprising that these cosmetic effects seriously undermine self-confidence.

There is no reason to conclude that long-term changes in adipose tissue such as HARS are unique or completely new. Other chronic infections, such as syphilis, whether transmitted by sexual intercourse or by other means, have probably caused comparable changes in physical appearance, and may even have contributed to the evolution of aversion to them.

\section{Crohn's disease}

Crohn's disease is a recurrent inflammatory disorder of the alimentary tract. Its causes are still not firmly established (Mishina et al. 1996); it may be a primary autoimmune disease in which the symptoms arise from sustained

Table 2. Some aspects of human biology relevant to the psychological distresses caused by HIV adipose redistribution syndrome

\begin{tabular}{|c|c|}
\hline \multicolumn{2}{|c|}{ Habits that promote accumulation and/or spread of pathogens } \\
\hline Longevity & More time in which to acquire diseases \\
\hline Sociality & Intimacy and large groups spread infections \\
\hline Prolonged parental care & Facilitates transmission from parent to offspring \\
\hline Omnivorous and carnivorous diet & Pathogens acquired from a wide range of prey animals \\
\hline Inhabiting caves and shelters & Decaying refuse and excreta accumulate, harbouring pathogens \\
\hline Wearing clothes & Harbours fleas, lice and other ectoparasites and transmits them to others \\
\hline Animal husbandry & Diseases acquired by prolonged intimate contact with domesticated livestock \\
\hline Food storage & Attracts commensal mice, rats etc. and their diseases \\
\hline \multicolumn{2}{|c|}{ Habits that curtail accumulation and/or spread of pathogens } \\
\hline Butchering prey & Parasites and poisonous tissues can be discarded; only 'clean' meat eaten \\
\hline Cooking food & Heat kills most microbes and animal parasites \\
\hline Seasonal migration between habitats & Limits reinfection from refuse and faeces \\
\hline Mates permanent and restricted to tribe & Sexual transmission of disease much reduced \\
\hline Living in small family groups & Reduces infection, especially for children \\
\hline Use of medicinal plants and minerals & Some expel intestinal parasites; others have antiseptic or other medicinal properties \\
\hline Grooming and washing & Removes superficial parasites \\
\hline \multicolumn{2}{|c|}{ Structures and habits that make adipose tissue an indicator of health } \\
\hline Hair reduction & Reveals details of body shape and complexion \\
\hline Erect posture & Abdomen, thorax and proximal segments of limbs become more visible \\
\hline $\begin{array}{l}\text { Communication by facial expressions and } \\
\text { postures }\end{array}$ & Social and sexual status and emotions displayed \\
\hline Low fecundity and parental care & Makes sexual selection more important \\
\hline Hunting in social groups & Sick or infective members impair the hunting success of the whole group \\
\hline
\end{tabular}


inflammatory responses to the normally benign microbes in the gut. Susceptibility is inherited, and several genes have been implicated (Peña, 1998), but the appearance of symptoms seems to require an environmental trigger. Diet is an obvious candidate, but infection with the widespread pathogen Mycobacterium paratuberculosis may be a factor in some cases.

Dr Burrill B. Crohn himself (Crohn et al. 1932) mentioned the characteristic appearance of mesenteric adipose tissue as a consistent symptom of the disease that bears his name; although nearly all patients become thin following prolonged disruption to appetite, digestion and absorption, the mesenteric adipose tissue near the diseased region of the gut is much enlarged (Sheehan et al. 1992). This distinctive symptom appears early in the course of the disease and, although the gross anatomy is obviously abnormal, Desreumaux et al. (1999) could find nothing unusual in the microscopical appearance of the adipocytes themselves.

The mRNA for tumour necrosis factor $\alpha$ and possibly other inflammatory cytokines are increased in the mesenteric adipocytes themselves, but not in other intraabdominal adipocytes or those from superficial depots (Desreumaux et al. 1999). Crohn's disease thus shares with HARS and NIDDM the peculiarity of selective expansion of certain adipose depots while others are depleted. There may also be some similarities in the inflammation of the intestinal mucosa in Crohn's disease and that of enteropathies associated with long-standing HIV infection (McGowan et al. 1997). The symptoms can occur even in patients whose immune responses are severely compromised by long-standing aggressive HIV infection (Lautenbach \& Lichtenstein, 1997). Crohn's disease also entails changes in fatty acid metabolism; the fatty acid compositions of phospholipids in blood cells and storage lipids in adipose tissue are anomalous, especially in individuals in whom active symptoms are long established (Geerling et al. 1999).

Although this anomalous hypertrophy of adipose tissue appears to be a primary defect in Crohn's disease (Sheehan et al. 1992; Desreumaux et al. 1999), it has not featured prominently in the extensive, and in many cases sophisticated, research into its pathology. Of more than 6000 papers about Crohn's disease published during the last 20 years, only eleven (less than $0.2 \%$ ) mention adipose tissue. This omission arises from the lack of understanding about biological principles that determine the distribution and anatomical relationships of adipose tissue that could form the basis of testable hypotheses.

\section{Special properties of perinodal adipose tissue}

In many naturally-lean wild animals most, sometimes all, of the visible adipose tissue surrounds the major lymph nodes and the heart, pericardium and great vessels, while the perirenal, epididymal and other 'typical' adipose depots usually chosen for study in laboratory animals are minimal (Pond, 1998). These observations prompted investigation into the special properties of adipose tissue anatomically associated with lymph nodes. The popliteal depot is well suited to such investigations because it contains only one large lymph node that is easy to stimulate locally. In adult guinea-pigs, the depot weighs about $1 \mathrm{~g}$, which provides enough tissue for study.

Co-incubation with mitogen-activated lymphoid cells causes lipolysis to rise approximately threefold in perinodal explants, a greater increase than is observed when isolated adipocytes are stimulated with large doses of noradrenaline (Pond \& Mattacks, 1995). Such effects are highly localized; adipose tissue from 1-2 $\mathrm{mm}$ around major lymph nodes may respond twice as much as neighbouring samples from $<1 \mathrm{~cm}$ away. The response of similar samples of adipose tissue from the large but nodeless perirenal depot is minimal compared with that observed in explants from the nodecontaining depots from the same animals, although these adipocytes respond satisfactorily to all other known local and blood-borne stimulants of lipolysis (Portillo et al. 1999). After $16 \mathrm{~h}$ of fasting, spontaneous lipolysis in adipocytes prepared from the perirenal depot and those from other nodeless depots such as the epididymal and parametrial is almost maximal, much higher than that from all perinodal adipocytes. The perinodal adipocytes are capable of large increases in lipolysis when stimulated in vitro with noradrenaline applied alone and after $24 \mathrm{~h}$ of incubation with various cytokines, particularly tumour necrosis factor $\alpha$ and interleukin 6 , but they do not respond nearly as strongly to the endocrine conditions of fasting (Mattacks \& Pond, 1999).

There are also differences in the fatty acid composition of triacylglycerols in adipose tissue from different parts of depots that contain lymph nodes. All perinodal adipocytes, especially those from the intermuscular, omental and mesenteric depots, contained fewer saturated fatty acids and more polyunsaturated fatty acids in their triacylglycerols than those elsewhere in the depots (Mattacks \& Pond, 1997). The abundance of monoenoic fatty acids was similar in all samples, although it can be altered by changing the dietary lipids. The immune system can utilise fatty acids as fuel and has specific requirements for certain $n-3$ and $n-6$ polyunsaturated fatty acids, many of them dietary essentials, as components of membranes and as precursors for eicosanoid synthesis (Calder, 1998). The fatty acids that the lymphoid cells need are more abundant in adipocytes anatomically located and biochemically equipped to supply them at short notice and avoid competition with other lipid-using tissues.

This concept is confirmed by in vivo studies. When a popliteal lymph node is activated with a small quantity of bacterial lipopolysaccharide, lipolysis in the adipocytes immediately surrounding it increases within $1 \mathrm{~h}$, and remains elevated for at least $9 \mathrm{~h}$ before declining almost to baseline after about $24 \mathrm{~h}$ (Fig. 1). A delayed, greatlyattenuated response is observed in homologous samples from the popliteal depot of the non-stimulated leg and in other perinodal samples. Noradrenaline-stimulated lipolysis remains normal in adipocytes thus activated, a synergism that suggests that the adipose tissue around the lymph nodes may be a forum for interactions between sympathetic stimulants such as stress and exercise, and immune function.

The portion of the popliteal adipose depot that displays the properties found in the perinodal samples increases if stimulation of the lymph node is repeated within 9-12 h. In Fig. 2, a single small dose of lipopolysaccharide $3 \mathrm{~h}$ before 


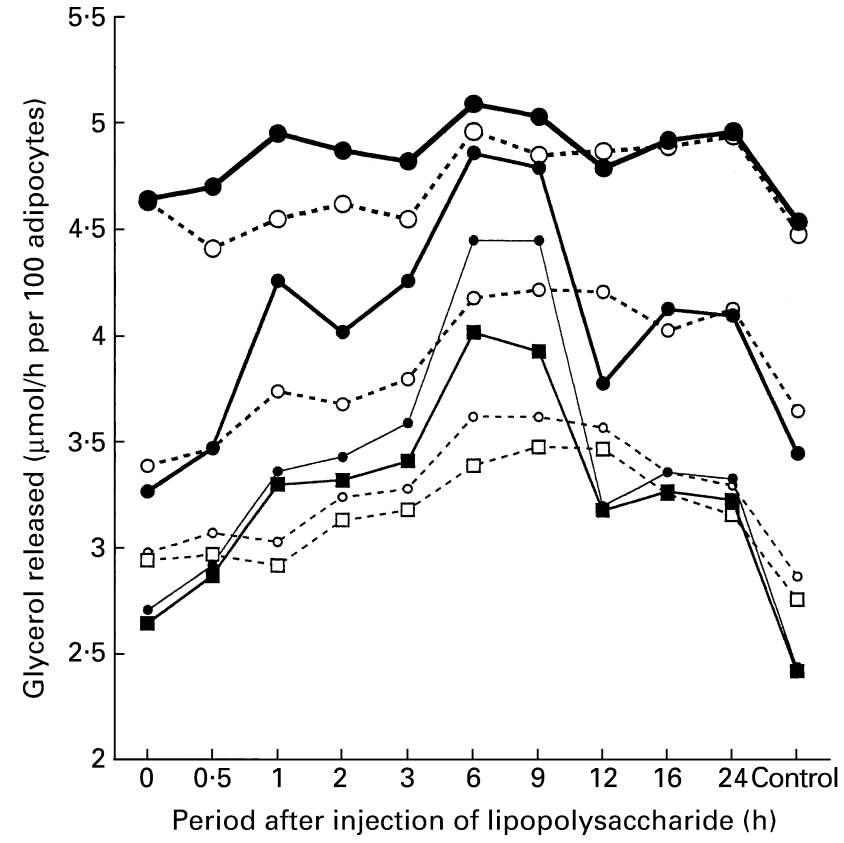

Fig. 1. Time course of spontaneous and noradrenaline-stimulated release of glycerol from popliteal adipocytes isolated from around the popliteal lymph node $(\bullet-\bullet-,-\bullet,--)$ and elsewhere in the depot $(\cdots \circ \cdots, \cdots \circ \cdots, \cdots \cdots, \cdots \square)$. To stimulate an immune response in this lymph node, approximately $10 \mu \mathrm{g}$ lipopolysaccharide/kg body mass was injected into the region of the skin that it drains, at the times indicated before death. Control was a sham injection of the same volume of sterile PBS $3 \mathrm{~h}$ before death. $(\mathbf{\square}, \mathrm{\square})$, No noradrenaline; $(\bullet-, \cdots \circ)$, noradrenaline at $10^{-8} \mathrm{M} ;(-\bullet, \cdots \circ), 10^{-7} \mathrm{M} ;(\bullet-$, -.--), $10^{-5}$ M. (Data from Pond \& Mattacks, 1998.)

death reverses the differences in the rate of lipolysis between the perinodal and remote-from-node and intermediate samples. When combined with a priming dose $9 \mathrm{~h}$ earlier, this treatment activates more of the popliteal node, so only the most remote sample is significantly different from the perinodal sample $(P<0 \cdot 02)$. With one or more even earlier doses the rates of lipolysis are not significantly different throughout the depot. In other words, simulating a prolonged or intensifying bacterial attack recruits more of the popliteal adipocytes to respond to the local secretions from the enclosed lymph node. These interactions between adipose tissue and the immune system are modulated by dietary lipids (Mattacks \& Pond, 1997; MacQueen et al. 2000), which may provide a route to its therapeutic manipulation.

After delays of the order of hours, perinodal adipocytes in depots remote from the site of stimulation are also activated, particularly mesenteric ones (CM Pond and CA Mattacks, unpublished results). In the experiment summarised in Fig. 3 , the guinea-pigs received one or two small doses of lipopolysaccharide injected subcutaneously into one hind leg (i.e. not near the abdomen). The effects of a single such dose given $3 \mathrm{~h}$ before death on lipolysis from adipocytes around the mesenteric lymph nodes and those more remote from nodes are very small. When combined with a previous dose administered 9 or $21 \mathrm{~h}$ earlier, this treatment greatly increases lipolysis in the perinodal samples only. Incubating samples as explants for $24 \mathrm{~h}$ with $10 \mathrm{ng}$ tumour necrosis

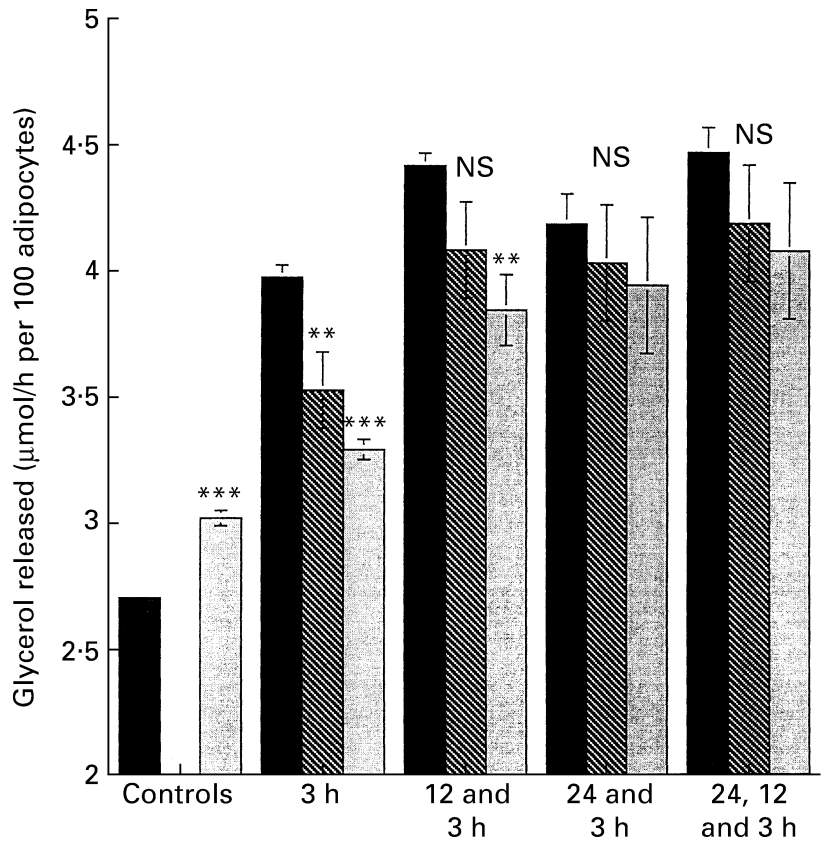

Times of injection(s) of lipopolysaccharide

Fig. 2. Spontaneous lipolysis from the perinodal popliteal adipocytes $(\square)$, adipocytes from about $10 \mathrm{~mm}$ away from the node $(\square)$ and adipocytes from the region in between (aw) after one, two or three subcutaneous injections into the ipsilateral hind leg of approximately $10 \mu \mathrm{g}$ lipopolysaccharide/kg body mass at combinations of 3,12 and $24 \mathrm{~h}$ before death (control is no injection). Values are means with their standard errors represented by vertical bars for six adult guineapigs per treatment. Mean values were significantly different from those for the corresponding perinodal samples: ${ }^{* *} P<0.02$, ${ }^{* * *} P<0 \cdot 001$. NS, not significant $(P>0 \cdot 05)$. (CM Pond and CA Mattacks, unpublished results.)

factor- $\alpha / \mathrm{ml}$ and $10 \mathrm{ng}$ interleukin- $4 / \mathrm{ml}$ before isolating the adipocytes reveals that this single dose at $3 \mathrm{~h}$ was detected by the mesenteric lymph nodes and their surrounding adipocytes, even though it did not produce any measurable change in glycerol release. The incubation suppressed lipolysis in the perinodal samples far below that of the remote-from-node samples and the values from untreated controls, to levels hardly different from those measured after repeated stimulation.

These experiments show that, as well as being very sensitive to small quantities of immune stimulants, perinodal mesenteric adipocytes 'remember' transient exposure for at least $21 \mathrm{~h}$. These properties could help to explain the abnormal growth and metabolism of adipose depots containing lymphoid tissue under chronic low-grade immune stimulation.

\section{Perinodal adipocytes and adipose tissue redistribution}

Table 1 mentions the hypothesis that excessive activation of perinodal adipose tissue causes HARS. HIV infection causes an abnormally high rate of turnover of lymphocytes in lymph nodes and other secondary immune tissues, sustained for long periods (Kaur et al. 2000). The mesenteric lymph nodes are heavily involved, as they are in 


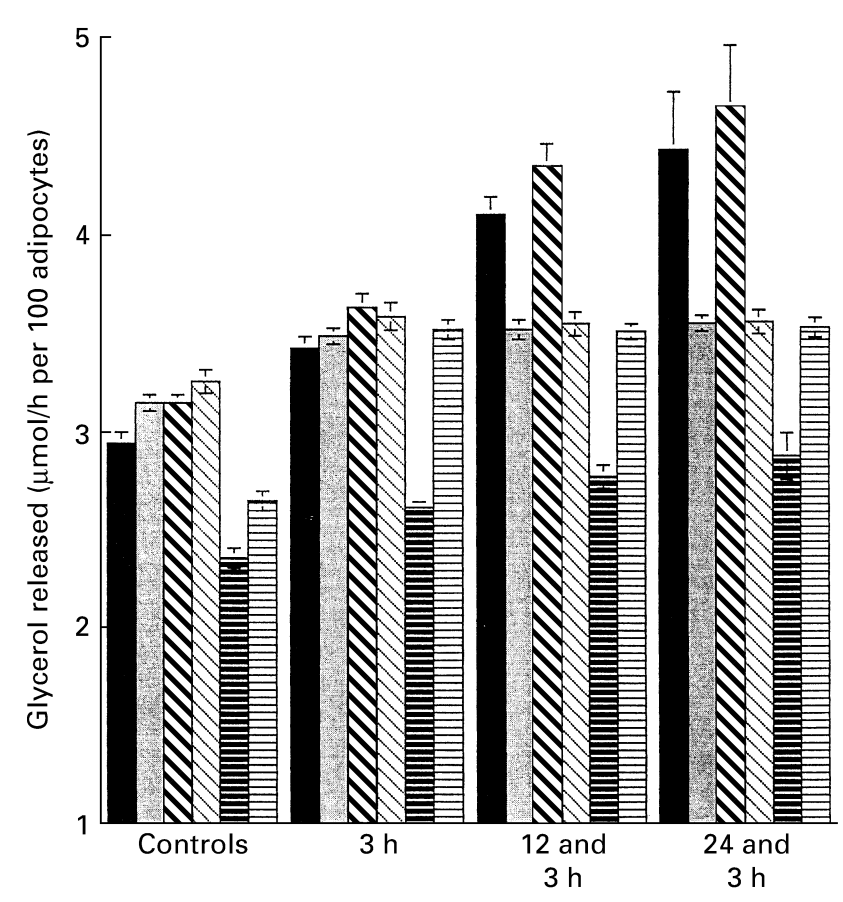

Times of injection(s) of lipopolysaccharide

Fig. 3. Spontaneous lipolysis from adipocytes from around mesenteric lymph nodes (darker bars) and about $10 \mathrm{~mm}$ away from the node (lighter bars), after one or two injections into the ipsilateral hind leg of approximately $10 \mu \mathrm{g}$ lipopolysaccharide/kg body mass, taken from guinea-pigs treated as in Fig. 2. Adipocytes were isolated from collagenase, and glycerol measurements were made within $4 \mathrm{~h}$ of excision of the tissue $(\square, \square)$, and after incubation of the adipose tissue as explants of $24 \mathrm{~h}$ without (av, alv) or with $10 \mathrm{ng}$ tumour necrosis factor- $\alpha$ and with $10 \mathrm{ng}$ interleukin 4 ( $\equiv, \equiv)$. Values are means with their standard errors represented by vertical bars for six adult guineapigs for each injection regimen. (CM Pond and CA Mattacks, unpublished results.)

feline immunodeficiency virus infection of domestic cats (Dean \& Pedersen, 1998) and in Crohn's disease.

The recognition of the special properties of perinodal adipocytes might explain site-specific expansion of nodecontaining depots as a long-term consequence of chronic inflammation arising from viral infection (HARS) or other inflammatory responses (Crohn's disease). The activated immune cells of the lymph nodes and other components of the secondary lymphoid system release signals that recruit adipose tissue more remote from nodes to acquire the properties of perinodal adipocytes, resulting in excess lipids in the blood (that are oxidized by other tissues) and enlargement of node-containing depots, of which the mesenteric is the largest and most active (Fig. 3). This shift to local control by lymphoid tissues diminishes sensitivity to the endocrine conditions of fasting, so that the adipose tissue thus altered becomes less available for whole-body energy storage. After months or years, these processes lead to depletion of the nodeless depots (such as thigh, buttock and superficial abdominal) that normally respond to fasting, and eventually to withdrawal of lipid from depots like the corpus adiposum buccae and eye socket, which are usually metabolically inert. The rate of change in body conformation can be modulated by many factors, including viral load and availability of essential fatty acids in the diet.
This hypothesis to explain HARS does not completely exclude contributions from impaired mitochondrial function and the other possible mechanisms listed in Table 1 . However, in contrast to the others, this hypothesis accounts for the known site-specific changes in adipose tissue, variability of symptoms and occurrence of HARS with untreated naturally-curtailed HIV infection, its development at constant or rising body mass and its anatomical similarities to Crohn's disease. According to this view, antiretroviral drugs curtail the proliferation of the virus sufficiently to keep the patient well enough for long enough to support the selective enlargement of perinodal adipose tissue in response to stimuli from the chronically-inflamed lymphoid tissues embedded within it. If there is insufficient spare lipid to support this growth, adipose tissue not associated with lymph nodes or omental milky spots is depleted, including eventually the metabolically-inert depots of the face and limbs. Direct interference with adipocyte metabolism by the drugs makes only a minor contribution, possibly none, to the reorganisation of the adipose mass.

Since Crohn's disease affects only the lymphoid tissues associated with the alimentary tract, selective growth of perinodal adipose tissue is limited to the mesenteric depot, which, as shown in Fig. 3, seems to be extremely sensitive to even very minor and distant immune stimuli. According to hypothesis, the changes in mesenteric adipose tissue would be similar whether such activation of immune processes arises from infection with a pathogen, food allergies or other autoimmune processes, or is idiopathic, arising from a genetic defect. It is thus consistent with most of the proposed causes of Crohn's disease.

Cytokines believed to mediate the interactions between activated lymph nodes and perinodal adipose tissue have also been reported as having a role in Crohn's disease. Desreumaux et al. (1999) found that tumour necrosis factor$\alpha$ is overexpressed in the hypertrophied mesenteric adipose tissue, and an impaired response to interleukin 4 is a symptom of Crohn's disease (Monteleone et al. 2000). An active role for perinodal adipose tissue is also consistent with the conclusions of Geerling et al. (1999) that abnormal lipid metabolism, rather than failure to absorb essential fatty acids from food, accounts for the anomalies of fatty acid composition of phospholipids in blood cells; this symptom takes many years to develop fully. Similar persistent changes in the fatty acid composition of lipids extracted from the blood have been found in HIV-positive undernourished children (Decsi \& Koletzko, 2000). They concluded that infection with HIV alters the metabolism of essential fatty acids, even in well-nourished, almost asymptomatic, subjects. The perinodal adipose tissue may be selectively accumulating certain polyunsaturated fatty acids, thereby depleting their availability for haematopoietic tissues. The problem may be exacerbated by malnutrition or poor nutrient absorption.

Infection with HIV and its treatment with antiviral drugs also cause premature loss of mineral from bone and other symptoms that resemble osteoporosis (Paton et al. 1997; Tebas et al. 2000). Abnormalities in bone formation also occur in children with severe obesity caused by a rare genetic deficiency in the production of leptin, a cytokine released from adipose tissue (Farooqi et al. 1998; Farooqi 
et al. 2000). The common mechanism may be the contribution of bone marrow adipocytes to bone formation (Gimble et al. 1996); in long-standing HIV infection, adipocytes are 'redeployed' to support failing immune function, as they are in HARS, so cannot contribute adequately to bone maintenance. The opposite may happen in genetically-obese children; too many mature adipocytes may accelerate skeletal maturation.

\section{Conclusions}

The identification of the special properties of perinodal adipocytes suggests mechanisms by which chronic inflammation could prompt certain adipose depots to expand at the expense of others, especially during periods of poor nutrient intake or absorption. Perinodal adipocytes are equipped to interact locally with lymph-node lymphoid cells, making polyunsaturated fatty acids selectively and almost instantly available to the immune cells when required, and without disrupting blood fatty acid levels and whole-body lipid metabolism. Their activities may have little or no manifestation in blood chemistry, which might explain the apparent independence of the anatomical changes from those of whole-body metabolism, i.e. insulin resistance, hyperlipidaemia etc. Further research using animal models as well as human patients is needed to establish whether these ideas lead to accurate explanations of the disease processes, and so to therapies for averting them.

\section{Acknowledgements}

I thank Dick Colby, Samantha Lucken, Chris Mattacks and Hilary MacQueen for comments on the manuscript.

\section{References}

Behrens GMN, Stoll M \& Schmidt RE (2000) Lipodystrophy syndrome in HIV infection. What is it, what causes it and how can it be managed? Drug Safety 23, 57-76.

Björntorp P (1996) The regulation of adipose-tissue distribution in humans. International Journal of Obesity 20, 291-302.

Björntorp P (1997) Body fat distribution, insulin resistance, and metabolic diseases. Nutrition 9, 795-803.

Brinkman K, Smeitink JA, Romijn JA \& Reiss P (2000) Mitochondrial toxicity of nucleoside analogue reverse transcriptase inhibitors: a looming obstacle for long-term antiretroviral therapy? Current Opinion in Infectious Diseases 13, 1112-1115.

Calder PC (1998) Dietary fatty acids and the immune system. Nutrition Reviews 56, S70-S83.

Carr A (2000) HIV protease inhibitor-related lipodystrophy syndrome. Clinical Infectious Diseases 30, S135-S142.

Chrousos GP (2000) The role of stress and the hypothalamicpituitary-adrenal axis in the pathogenesis of the metabolic syndrome: neuroendocrine and target tissue-related causes. International Journal of Obesity 24, S50-S55.

Crohn BB, Ginzburg L \& Oppenheimer GD (1932) Regional ileitis, a pathologic and clinical entity. Journal of the American Medical Association 99, 1323-1329.

Dean GA \& Pedersen NC (1998) Cytokine response in multiple lymphoid tissues during the primary phase of feline immunodeficiency virus infection. Journal of Virology 72, 9436-9440.

Decsi T \& Koletzko B (2000) Effects of protein-energy malnutrition and human immunodeficiency virus-1 infection on essential fatty acid metabolism in children. Nutrition $\mathbf{1 6}$, $447-453$.

de la Asuncion JG, del Olmo ML, Sastre J, Millan A, Pellin A, Pallardo FV \& Vina J (1998) AZT treatment induces molecular and ultrastructural oxidative damage to muscle mitochondria: Prevention by antioxidant vitamins. Journal of Clinical Investigation 102, 4-9.

Desreumaux P, Ernst O, Geboes K, Gambiez L, Berrebi D, MüllerAlouf H, Hafraoui S, Emilie D, Ectors N, Peuchmaur M, Cortot A, Capron M, Auwerx J \& Colombel JF (1999) Inflammatory alterations in mesenteric adipose tissue in Crohn's disease. Gastroenterology 117, 73-81.

Dhurandhar N, Kulkarni PR, Ajinkya SM, Sherikar AA \& Atkinson RL (1997) Association of adenovirus infection with human obesity. Obesity Research 5, 464-469.

Digby JE (1998) The role of different adipose depots in glutamine metabolism following feeding, fasting and exercise in the guinea-pig. PhD Thesis, The Open University.

Dong KL, Bausserman LL, Flynn MM, Dickinson BP, Flanigan TP, Mileno MD, Tashima KT \& Carpenter CCJ (1999) Changes in body habitus and serum lipid abnormalities in HIV-positive women on highly active antiretroviral therapy (HAART). Journal of Acquired Immune Deficiency Syndromes and Human Retrovirology 21, 107-113.

Ellis RW (1997) Infection and coronary heart disease. Journal of Medical Microbiology 46, 535-539.

Engelson ES, Kotler DP, Tan YX, Agin D, Wang J, Pierson RN \& Heymsfield SB (1999) Fat distribution in HIV-infected patients reporting truncal enlargement quantified by whole-body magnetic resonance imaging. American Journal of Clinical Nutrition 69, 1162-1169.

Farooqi IS, Yeo GSH, Keogh JM, Aminian S, Jebb SA, Butler G, Cheetham T \& O'Rahilly S (2000) Dominant and recessive inheritance of morbid obesity associated with melanocortin 4 receptor deficiency. Journal of Clinical Investigation 106, 271-279.

Farooqi S, Rau H, Whitehead J \& O'Rahilly S (1998) $o b$ gene mutations and human obesity. Proceedings of the Nutrition Society 57, 471-475.

Folstad I \& Karter AJ (1992) Parasites, bright males, and the immunocompetence handicap. American Naturalist 139, 603-622.

Frayn KN (2000) Visceral fat and insulin resistance - causative or correlative? British Journal of Nutrition 83, S71-S77.

Frayn KN, Khan K, Coppack SW \& Elia M (1991) Amino acid metabolism in human subcutaneous adipose tissue in vivo. Clinical Science 80, 471-474.

Geerling BJ, van Houwelingen AC, Badart-Smook A, Stockbrugger RW \& Brummer JM (1999) Fat intake and fatty acid profile in plasma phospholipids and adipose tissue in patients with Crohn's disease, compared with controls. American Journal of Gastroenterology 94, 410-417.

Gerschenson M, Erhart SW, Paik CY, St Claire MC, Nagashima K, Skopets B, Harbaugh SW, Harbaugh JW, Quan W \& Poirier MC (2000) Fetal mitochondrial heart and skeletal muscle damage in Erythrocebus patas monkeys exposed in utero to 3'-azido-3'deoxythymidine. AIDS Research and Human Retroviruses 16, 635-644.

Gervasoni C, Ridolfo AL, Trifirò G, Santambrogio S, Norbiato G, Musicco M, Clerici M, Galli M \& Moroni M (1999) Redistribution of body fat in HIV-infected women undergoing combined antiretroviral therapy. AIDS 13, 465-471.

Gimble JM, Robinson CE, Wu X \& Kelly KA (1996) The function of adipocytes in the bone marrow stroma: an update. Bone 19, 421-428.

Grünfeld C \& Feingold KR (1992) Tumor necrosis factor, interleukin, and interferon induced changes in lipid metabolism as 
part of host defense. Proceedings of the Society for Experimental Biology and Medicine 200, 224-227.

Hatano H, Miller KD, Yoder CP, Yanovski JA, Sebring NG, Jones EC \& Davey RT (2000) Metabolic and anthropometric consequences of interruption of highly active antiretroviral therapy. AIDS 14, 1935-1942.

Horrobin D (1992) The relationship between schizophrenia, essential fatty acids and eicosanoid metabolism. Prostaglandins, Leukotrienes and Essential Fatty Acids 47, 71-77.

Jaquet D, Lévine M, Ortega-Rodriguez E, Faye A, Polak M, Vilmer E \& Lévy-Marchal C (2000) Clinical and metabolic presentation of the lipodystrophic syndrome in HIV-infected children. AIDS 14, 2123-2128.

Kaur A, Rosenzweig M \& Johnson RP (2000) Immunological memory and acquired immunodeficiency syndrome pathogenesis. Philosophical Transactions of the Royal Society of London 355B, 381-390.

Kolson DL, Lavi E \& González-Scarano F (1998) The effects of human immunodeficiency virus in the central nervous system. Advances in Virus Research 50, 1-47.

Kotler DP, Rosenbaum K, Wang J \& Pierson RN (1999) Studies of body composition and fat distribution in HIV-infected and control subjects. Journal of Acquired Immune Deficiency Syndromes and Human Retrovirology 20, 228-237.

Laugharne JDE, Mellor JE \& Peet M (1996) Fatty acids and schizophrenia. Lipids 31, S163-S175.

Lautenbach E \& Lichtenstein GR (1997) Human immunodeficiency virus infection and Crohn's disease: The role of the CD4 cell in inflammatory bowel disease. Journal of Clinical Gastroenterology 25, 456-459.

Lonn L, Kvist H, Ernest I \& Sjöström L (1994) Changes in body-composition and adipose tissue distribution after treatment of women with Cushing's syndrome. Metabolism 43, $1517-1522$.

McGowan IM, Fairhurst RM, Shanahan F \& Anton PA (1997) Mucosal substance $\mathrm{P}$ receptor expression in HIV infection and inflammatory bowel disease. Neuroimmunomodulation 4, 70-76.

MacQueen HA, Sadler D \& Mattacks CA (2000) Dietary fatty acids influence the appearance of tumour necrosis factor- $\alpha$ receptors on adipocytes following an immune challenge. British Journal of Nutrition 84, 387-392.

Madge S, Kinloch-de-Loes S, Mercey D, Johnson MA \& Weller IVD (1999) Lipodystrophy in patients naive to HIV protease inhibitors. AIDS 13, 735-737.

Mattacks CA \& Pond CM (1997) The effects of feeding suetenriched chow on site-specific differences in the composition of triacylglycerol-fatty acids in adipose tissue and its interactions in vitro with lymphoid cells. British Journal of Nutrition 77, 621-643.

Mattacks CA \& Pond CM (1999) Interactions of noradrenalin and tumour necrosis factor- $\alpha$, interleukin- 4 and interleukin- 6 in the control of lipolysis from adipocytes around lymph nodes. Cytokine 11, 334-346.

Mauss S (2000) HIV-associated lipodystrophy syndrome. AIDS 14, Suppl. 3, S197-S207.

Miller T (2000) Nutrition in paediatric human immunodeficiency virus infection. Proceedings of the Nutrition Society 59, 155-162.

Mishina D, Katsel P, Brown ST, Gilberts ECAM \& Greenstein RJ (1996) On the etiology of Crohn disease. Proceedings of the National Academy of Sciences USA 93, 9816-9820.

Mohamed-Ali V, Pinkney JH \& Coppack SW (1998) Adipose tissue as an endocrine and paracrine organ. International Journal of Obesity 22, 1145-1158.

Monteleone G, Biancone L, Wedel S \& Pallone F (2000) IL-4 hyporesponsiveness of Crohn's disease mucosal T lymphocytes: a response of polarised Th1 cells? Digestive and Liver Disease 32, 495-497.

Moyle G (2000) Clinical manifestations and management of antiretroviral nucleoside analog-related mitochondrial toxicity. Clinical Therapeutics 22, 911-936.

Panse I, Vasseur E, Raffin-Sanson ML, Staroz F, Rouveix E \& Saiag P (2000) Lipodystrophy associated with protease inhibitors. British Journal of Dermatology 142, 496-500.

Paton N, Macallan DC, Griffin GE \& Pazianas M (1997) Bone mineral density in patients with human immunodeficiency virus infection. Calcified Tissue International 61, 30-32.

Peña AS (1998) Genetics of inflammatory bowel disease - the candidate gene approach: susceptibility versus disease heterogeneity. Digestive Diseases 16, 356-363.

Pond CM (1998) The Fats of Life. Cambridge: Cambridge University Press.

Pond CM (1999) Physiological specialisation of adipose tissue. Progress in Lipid Research 38, 225-248.

Pond CM \& Mattacks CA (1995) Interactions between adipose tissue around lymph nodes and lymphoid cells in vitro. Journal of Lipid Research 36, 2219-2231.

Pond CM \& Mattacks CA (1998) In vivo evidence for the involvement of the adipose tissue surrounding lymph nodes in immune responses. Immunology Letters 63, 159-167.

Portillo MP, Tueros AI, Perona JS, Ruiz-Gutiérrez V, Torres I \& Macarulla MT (1999) Modifications induced by dietary lipid source in adipose tissue phospholipid fatty acids and their consequences for lipid mobilization. British Journal of Nutrition $\mathbf{8 2}$ 319-327.

Safrin S \& Grünfeld C (1999) Fat distribution and metabolic changes in patients with HIV infection. AIDS 13, 2493-2505.

Saint-Marc T, Partisani M, Poizot-Martin I, Bruno F, Rouvière O, Lang J-M, Gastaut J-A \& Touraine J-L (1999) A syndrome of peripheral fat wasting (lipodystrophy) in patients receiving longterm nucleoside analogue therapy. AIDS 13, 1659-1667.

Saint-Marc T, Partisani M, Poizot-Martin I, Rouvière O, Bruno F, Avellaneda R, Lang J-M, Gastaut J-A \& Touraine J-L (2000) Fat distribution evaluated by computed tomography and metabolic abnormalities in patients undergoing antiretroviral therapy: preliminary results of the LIPOCO study. AIDS 14, 37-49.

Shaw AJ, McLean KA \& Evans BA (1998) Disorders of fat distribution in HIV infection. International Journal of STD and AIDS 9, 595-599.

Sheehan AL, Warren BF, Gear MWL \& Shepherd NA (1992) Fatwrapping in Crohn's disease: pathological basis and relevance to surgical practice. British Journal of Surgery 79, 955-958.

Singh D (1993) Adaptive significance of female physical attractiveness: the role of waist-to-hip ratio. Journal of Personality and Social Psychology 654, 293-307.

Singh D (1995a) Female health, attractiveness, and desirability for relationships: Role of breast asymmetry and waist-to-hip ratio. Ethology and Sociobiology 16, 465-481.

Singh D (1995b) Female judgment of male attractiveness and desirability for relationships: role of waist-to-hip ratio and financial status. Journal of Personality and Social Psychology 69, 1089-1101.

Singh D \& Bronstad PM (1997) Sex differences in the anatomical locations of human body scarification and tattooing as a function of pathogen prevalence. Evolution and Human Behavior 18, 403-416.

Singh D \& Luis S (1995) Ethnic and gender consensus for the effect of waist-to-hip ratio on judgment of women's attractiveness. Human Nature 6, 51-65.

Singh D \& Young RK (1995) Body weight, waist-to-hip ratio, breasts, and hips: role in judgments of female attractiveness and desirability for relationships. Ethology and Sociobiology 16, 483-507. 
Tebas P, Powderly WG, Claxton S, Marin D, Tantisiriwat W, Teitelbaum SL \& Yarasheski KE (2000) Accelerated bone mineral loss in HIV-infected patients receiving potent antiretroviral therapy. AIDS 14, F63-F67.

Torpy DJ, Bornstein SR \& Chrousos GP (1998) Leptin and interleukin-6 in sepsis. Hormone and Metabolic Research 30, 726-729.

Vigouroux C, Gharakhanian S, Salhi Y, Nguyen TH, Chevenne D, Capeau J \& Rozenbaum W (1999) Diabetes, insulin resistance and dyslipidaemia in lipodystrophic HIV-infected patients on highly active antiretroviral therapy (HAART). Diabetes and Metabolism 25, 225-232.

Yolken RH, Karlsson H, Yee F, Johnston-Wilson NL \& Torrey EF (2000) Endogenous retroviruses and schizophrenia. Brain Research Reviews 31, 193-199.

Zuk M (1996) Disease, endocrine-immune interactions, and sexual selection. Ecology 77, 1037-1042. 